Formatif: Jurnal Ilmiah Pendidikan MIPA

Vol. 8, No. 1, April 2018, pp. 1-6

p-ISSN: 2088-351X

e-ISSN: 2502-5457

DOI: http://dx.doi.org/10.30998/formatif.v8i1.2304

\title{
Motivation Analysis Learning in The Implementation of Physics Practicum
}

\author{
Analisis Motivasi Belajar Dalam Pelaksanaan Praktikum Fisika \\ Muhammad Syahrul Kahar \\ Universitas Muhammadiyah Sorong \\ Jalan Pendidikan No. 27 Sorong
}

\begin{abstract}
Physics learning aims to gain an understanding of facts, the ability to recognize and solve problems on an object, and have a scientific attitude that can be demonstrated in everyday reality. With the development of curriculum in universities, students are allowed to further hone their skills in following the learning in the classroom. The method used in this research is quantitative approach by using questionnaire of learning motivation, learning result as a data source. The population at the same time the subject used is Civil Engineering student class A with total 35 students. The results showed that the average student learning outcomes were 74,65 , the standard deviation of 5.37 with the highest score was in the score of 85.00 and the lowest score was 66.00 , the learning motivation scores were in the 100-130 interval for the high category, score $0-80$ medium category. Regression test results obtained tcount: $7,54>$ table: 1.68 , with a significance level of 0.05 . So the motivation to learn students in the implementation of lab laboratory is very supportive students in construct knowledge and skills possessed. The conclusion in this research is the need of improvement from the aspect of student's learning motivation in following the learning or the implementation of practicum activities so that the learning outcomes obtained are satisfactory.
\end{abstract}

Keywords: Motivation learning, study, practicum.

(*) Corresponding Author: $\quad$ E-mail : fmuhammadsyahrulkahar@gmail.com, No. Hp: 08114850190.

How to Cite:. Kahar, M.S. (2018). Motivation analysis learning in the implementation of physics practicum. Formatif: Jurnal Ilmiah Pendidikan MIPA, 8 (1): 1-6. http://dx.doi.org/10.30998/formatif.v8i1.2304.

\section{PENDAHULUAN}

Pembelajaran fisika bertujuan untuk memperoleh pemahaman tentang berbagai fakta, kemampuan mengenal dan memecahkan masalah terhadap suatu objek, dan mempunyai sikap ilmiah yang dapat ditunjukkan pada kenyataan sehari-hari. Dengan adanya pengembangan kurikulum di perguruan tinggi, dimungkinkan mahasiswa untuk lebih mengasah keterampilannya dalam mengikuti pembelajaran di kelas.

Kegiatan praktikum merupakan sebuah metode yang dapat memberikan pengaruh signifikan terhadap keberhasilan mahasiwa dalam mengikuti proses pembelajaran. Melalui kegiatan ini, mahasiswa mampu mengamati secara langsung objek, melatih keterampilan berpikir, bersikap ilmiah, dan dapat memecahkan masalah melalui metode ilmiah. Oleh sebab itu, perlu adanya laboratorium yang mampu untuk mendukung keberhasilan pembelajaran fisika di kelas, agar pemahaman mahasiswa akan materi yang disampaikan menjadi lebih komprehensif. (Kahar, 2017).

Kegiatan laboratorium tentunya harus memenuhi standarisasi keberhasilan pembelajaran yakni tersedianya sarana dan prasarana minimal yang baik. Namun pada 
Formatif: Jurnal Ilmiah Pendidikan MIPA

Vol. 8, No. 1, April 2018, pp. 1-6

p-ISSN: 2088-351X

e-ISSN: $2502-5457$

DOI: http://dx.doi.org/10.30998/formatif.v8i1.2304

hakikatnya masih banyak hal yang perlu ditingkatkan di laboratorium khususnya pada keberadaan alat laboratorium, hal ini terlihat pada pengamatan selama di laboratorium fisika yakni minimnya alat-alat yang ada sehingga pendidik harus mampu mengkreasikan segala kemampuannya dengan keberadaan alat yang tersedia. Menurut Hasibuan dan Moedjiono (2009), kegiatan praktikum efektif apabila: 1. Rumusan yang jelas tentang kecakapan atau keterampilan yang didapatkan setelah melakukan praktikum. 2. Metode praktikum yang wajar digunakan. 3. Alat-alat yang digunakan mudah didapat dan telah dicoba terlebih dahulu. 4. Jumlah mahasiswa memungkinkan untuk diadakan praktikum. 5. Menetapkan garis-garis besar langkah-langkah yang akan dilaksanakan sebelum praktikum. 6. Memperhitungkan waktu yang dibutuhkan untuk kegiatan praktikum. 7. Keterangan yang disampaikan asisten laboratorium didengar jelas oleh praktikan dan alatalat ditempatkan pada posisi yang baik sehingga setiap mahasiswa dapat melihat dengan jelas selama kegiatan praktikum berlangsung.

Hasil pengamatan menggambarkan bahwa sebagian besar mahasiswa lebih fokus dalam menyelesaikan laporan lengkap pada kegiatan praktikum ketimbang memahami pengetahuan yang didasarkan pada aktivitas kegiatan praktikum Fisika sehingga hasil belajar yang didapat tidak bermakna bagi mahasiswa. Oleh sebab itu, mahasiswa yang memperoleh skor tinggi dalam pembelajaran fisika menunjukkan ketidakmampuan dalam menerapkan apa yang diperolehnya, baik dalam implementasi pengetahuan, keterampilan maupun sikap ilmiah ke dalam lingkungannya. Selain itu, kegiatan ini juga pada dasarnya mampu menumbuhkan motivasi belajar mahasiswa, sehingga dalam proses pembelajaran mampu meningkatkan hasil belajar. Motivasi ini juga dapat dilihat dari dua aspek meliputi: a) Motivasi sebagai sebab, yaitu kekuatan pendorong yang memaksa seseorang menaruh perhatian pada orang, situasi atau aktivitas tertentu dan bukan pada yang lain, dan b) Motivasi sebagai akibat, yaitu pengalaman efektif yang distimulir oleh hadirnya seseorang atau suatu objek atau karena partisipasi dalam suatu aktivitas, (Dwija, 2008).

Hal ini didukung oleh Puspitorini et.al (2014), Adinugraha (2017), dan Apriyani, (2017), menyatakan bahwa penggunaan media di dalam pembelajaran IPA mampu meningkatkan motivasi belajar dengan rata-rata hasil belajar meningkat pada kategori sedang, sehingga menunjukkan adanya perbedaan yang signifikan terhadap motivasi belajar. Selain itu, penggunaan alat-alat dalam pelaksanaan praktikum dapat digunakan untuk menjelaskan fakta dan fenomena yang ada. Rasul et.al (2011), dan King et.al (2007) memaparkan bahwa belajar merupakan sebuah bentuk kemampuan dalam menghubungkan informasi ke konteks yang lebih perspektif, seperti kemampuan menghubungkan gagasan dengan kondisi nyata. Di sisi lain Kahar (2017) juga menjelaskan minat belajar, motivasi belajar dan hasil belajar mahasiswa sangat bergantung pada metode atau cara yang dilakukan oleh pendidik dalam mengelaborasi pembelajaran melalui berbagai kegiatan baik pelaksaanaan praktikum di laboratorium atau memberikan sebuah alat peraga di kelas.

Tujuan dalam penelitian ini adalah untuk (1) mengetahui motivasi belajar mahasiswa dalam pelaksanaan praktikum, (2) mengetahui hasil belajar yang didapatkan setelah pelaksanaan praktikum.

\section{METODE}

Penelitian ini merupakan penelitian deskriptif kuantitatif. Penelitian ini termasuk penelitian deskriptif kuantitatif karena bertujuan memaparkan hasil motivasi belajar mahasiswa setelah mengikuti proses pelaksanaan praktikum fisika di laboratorium. Populasi dan Sampel Penelitian ini adalah mahasiswa Program studi Teknik Sipil kelas A dengan jumlah mahasiswa 35 mahasiswa. Pengumpulan data yang digunakan dalam 
Formatif: Jurnal Ilmiah Pendidikan MIPA

Vol. 8, No. 1, April 2018, pp. 1-6

p-ISSN: 2088-351X

e-ISSN: 2502-5457

DOI: http://dx.doi.org/10.30998/formatif.v8i1.2304

penelitian ini adalah angket dan tes hasil belajar. Jenis angket yang digunakan yaitu angket motivasi belajar dengan skala pengukuran dalam bentuk checklist. Teknik analisis data yang digunakan adalah (1) Analisis hasil belajar dilakukan untuk mengetahui perkembangan hasil belajar mahasiswa setelah dilakukan pemberian praktikum, dan (2) Analisis hasil motivasi belajar yang didasarkan pada skor motivasi yang didapatkan dengan menggunakan analisis grafik.

\section{HASIL DAN PEMBAHASAN}

\section{Hasil}

Berdasarkan hasil pelaksanaan penelitian di laboratorium, didapatkan rata-rata hasil belajar mahasiswa selama pelaksanaan kegiatan seperti pada Gambar 1.

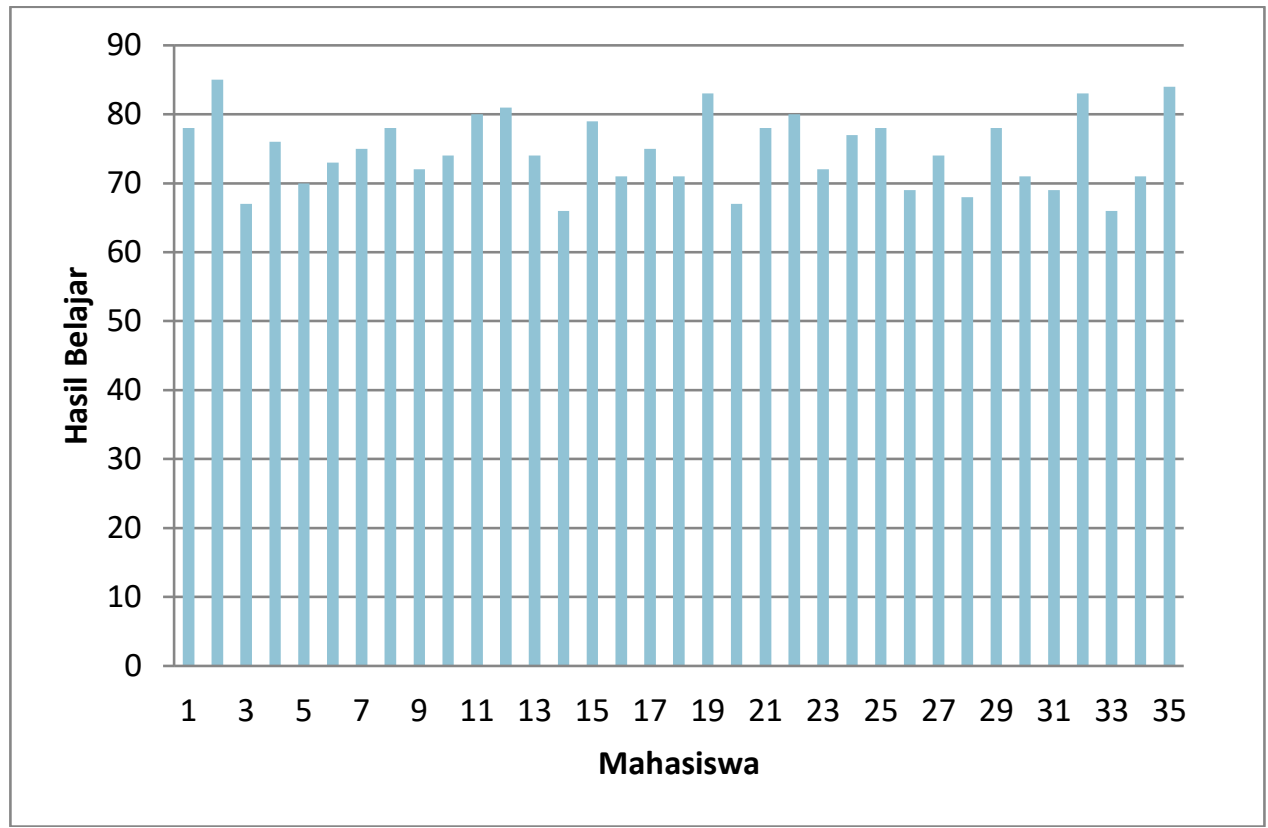

Gambar 1. Skor Hasil Belajar Mahasiswa

Gambar 1. menunjukkan bahwa hasil belajar mahasiswa dengan jumlah 35 mahasiswa ratarata 74,65, standar deviasi 5,37 dengan skor tertinggi berada pada skor 85,00 dan skor terendah 66,00 . Hal ini memperjelas bahwa proses pelaksanaan praktikum yang dilakukan di laboratorium menghasilkan hasil belajar yang lebih baik dibandingkan pada pembelajaran konvensional. Hal ini dikarenakan pada kegiatan praktikum mahasiswa diberikan kesempatan untuk dapat mengobservasi, menelah, mengamati, dan melakukan praktikum secara berkelompok terhadap unit percobaan atau materi yang dipraktikumkan. Selanjutnya motivasi belajar yang diperoleh mahasiswa dapat dilihat pada gambar 2 . 
Formatif: Jurnal Ilmiah Pendidikan MIPA

Vol. 8, No. 1, April 2018, pp. 1-6

p-ISSN: 2088-351X

e-ISSN: 2502-5457

DOI: http://dx.doi.org/10.30998/formatif.v8i1.2304

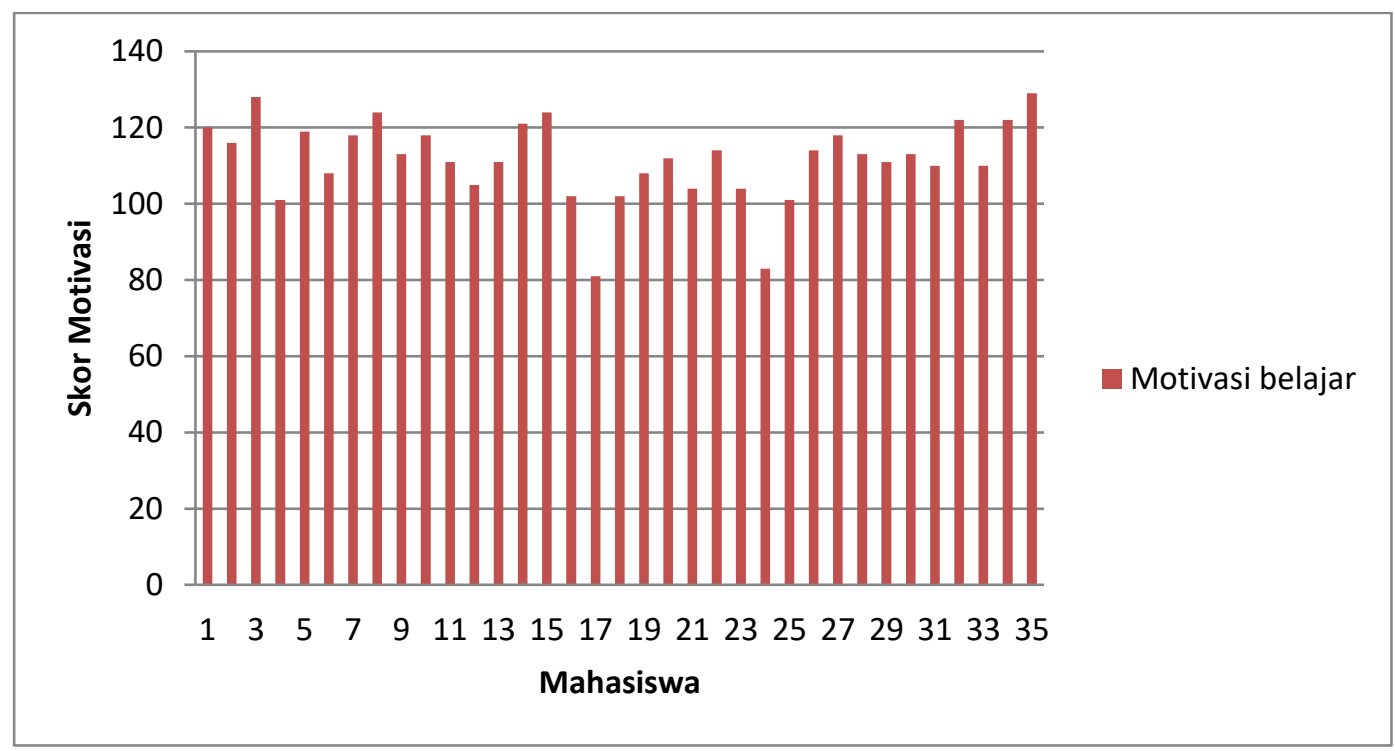

Gambar 2. Skor Motivasi Belajar Mahasiswa

Gambar 2 menunjukkan bahwa rata-rata perolehan skor motivasi belajar mahasiswa berada di interval 100-130 untuk kategori tinggi, skor 0-80 kategori sedang. Menganalisis hasil diperoleh mahasiswa dapat dijelaskan bahwa pelaksanaan praktikum sangat membantu mahasiswa dalam memahami materi, unit percobaan dan mampu untuk menjelaskan lebih nyata terkait fenomena disekitarnya. Dengan demikian dapat dikatakan pembelajaran yang berorientasi pada pelaksanaan praktikum sangat membantu mahasiswa dalam memahami materi yang diajarkan, hal ini sesuai dengan hasil uji Pengaruh antara motivasi belajar dengan hasil belajar mahasiswa yang diperoleh, seperti pada tabel 1 .

Tabel 1. Pengaruh antara Motivasi Belajar dengan Hasil Belajar

\begin{tabular}{|c|c|c|c|c|}
\hline \multicolumn{5}{|c|}{ Koefisien } \\
\hline \multirow[t]{2}{*}{ Model } & \multicolumn{2}{|c|}{ Koefisien Standar } & \multirow[t]{2}{*}{$\mathrm{t}$} & \multirow[t]{2}{*}{ Sig. } \\
\hline & $\mathrm{B}$ & Std. Error & & \\
\hline Konstan & 74,64 & 9,89 & 7,54 & 0,00 \\
\hline Motivasi terhadap hasil belajar & 0,00 & 0,08 & 0,00 & 0,99 \\
\hline
\end{tabular}

Jika menganalisis hasil uji regresi tersebut didapatkan bahwa nilai $\mathrm{t}_{\text {hitung }}: 7,54>\mathrm{t}_{\text {tabel }}: 1,68$, dengan taraf signifikansi 0,05. Hal ini menjelaskan bahwa Pada motivasi belajar mahasiswa terhadap hasil belajar memiliki pengaruh yang signifikan terhadap kemauan mahasiswa untuk mengikuti pembelajaran di kelas yang berorientasi pada pelaksanaan praktikum pada setiap materi yang diajarkan.

\section{Pembahasan}

Berdasarkan hasil yang didapatkan untuk hasil belajar mahasiswa terlihat bahwa perolehan rata-rata hasil belajar berada dikisaran 74,65 dengan tertinggi pada pelaksanaan praktikum sebesar 85,00 . Sedangkan untuk motivasi belajar mahasiswa rata-rata berada dikategori sedang sampai dengan tinggi dengan skor tertinggi 130 dan skor terendah 80 . Oleh karena itu dapat disimpulkan bahwa motivasi belajar pada kegiatan praktikum sangat membantu mahasiswa menerapkan dan mengeksplorasi kemampuannya dalam menyelesaikan permasalahan yang berikan pada saat melaksanakan praktik di laboratorium. Hal ini didukung oleh Kahar (2017) yang menjelaskan bahwa pemahaman 
Formatif: Jurnal Ilmiah Pendidikan MIPA

Vol. 8, No. 1, April 2018, pp. 1-6

p-ISSN: 2088-351X

e-ISSN: 2502-5457

DOI: http://dx.doi.org/10.30998/formatif.v8i1.2304

mahasiswa terhadap suatu materi pembelajaran terbentuk dengan adanya kegiatan praktikum dengan tingkat pemahaman yang lebih baik. (Shui-fong Lam. 2009) yang menunjukkan bahwa pembelajaran yang dilakukan dengan berorientasi pada pemecahan masalah mampu untuk meningkatkan motivasi belajar mahasiswa selama mengikuti proses pembelajaran di kelas, selain itu, hasil belajar yang didapatkan juga menjadi lebih baik.

Pada hasil uji regresi yang didapatkan memperlihatkan bahwa nilai $t_{\text {hitung }}: 7,54>t$ tabel: 1,68 ,dengan taraf signifikansi 0,05 , ini memaparkan bahwa motivasi belajar mahasiswa memiliki pengaruh yang signifikan terhadap hasil belajar yang diperoleh, sehingga sangat perlu dirancang kembali metode pembelajaran yang kreatif yang berorientasi pada pencarian dan pengamatan terhadap suatu objek di laboratorium. pelaksanaan praktikum mampu memberikan umpan balik dan mengkonstruksi pengetahuan mahasiswa ke arah positif. Pembelajaran yang berorintasi kegiatan praktikum bisa membantu para mahasiswa untuk belajar lebih baik, dan membangun kemampuan dan kepercayaan mereka untuk mengevaluasi pengetahuan yang mereka miliki. Selain itu, mereka bisa meningkatkan motivasi terhadap materi yang diajarkan. mahasiswa lebih aktif dalam berinteraksi dengan kelompok yang dibuat dan aktif dalam mengkonstruksi pengetahuan yang dimiliki (Savander-Ranne \& Kolari, 2003).

Hal ini juga didukung oleh Penelitian (Assor et.al. 2005) yang menjelaskan bahwa pendidik merupakan kontrol pengendalian dari sebuah kegiatan pembelajaran baik yang dilaksanakan di laboratorium dalam bentuk kegiatan praktikum maupun dalam kelas memiliki pengaruh terhadap peningkatan motivasi belajar dan juga keterampilan mahasiswa dalam melakukan kegiatan praktikum.

\section{PENUTUP}

Berdasarkan hasil penelitian yang dilaksanakan menggambarkan bahwa Tingkat rata-rata keberhasilan yang diperoleh mahasiswa selama mengikuti kegiatan praktikum berada pada rata-rata 74,65 dengan level keberhasilan berada dikategori baik. Disisi lain, tingkat pencapaian motivasi belajar mahasiswa selama mengikuti praktikum dibagi dalam dua kategori yakni untuk interval skor 100-130 untuk kategori tinggi, skor 0-80 kategori sedang. keberhasilan ini juga ditunjang dari aspek pengaruhnya terhadap hasil belajar yang menunjukkan ada pengaruh yang signifikan terhadap motivasi belajar mahasiswa dalam mengikuti proses-proses dalam kegiatan praktikum fisika dengan interpretasi yang dinyatakan dari nilai $t_{\text {hitung }}: 7,54>\mathrm{t}_{\text {tabel }}: 1,68$, oleh karena itu, perlu adanya peningkatan dari aspek motivasi belajar mahasiswa dalam mengikuti pembelajaran atau pelaksanaan kegiatan praktikum agar hasil belajar yang didapatkan memuaskan. Selain itu proses pembelajaran yang berkesinambungan dalam mengeksplorasi kemampuan mahasiswa dalam memahami suatu materi pembelajaran khususnya materi fisika, sehingga hasil belajar yang didapatkan selalu memiliki kebermanfaatan terhadap segala aspek yang diukur.

\section{DAFTAR PUSTAKA}

Assor, A., Kaplan, H., Kanat-Maymon, Y., \& Roth, G. (2005). Directly controlling teacher behaviors as predictors of poor motivation and engagement in girls and boys: The role of anger and anxiety. Learning and Instruction, 15(5), 397-413. https://doi.org/10.1016/j.learninstruc.2005.07.008 
Formatif: Jurnal Ilmiah Pendidikan MIPA

Vol. 8, No. 1, April 2018, pp. 1-6

p-ISSN: 2088-351X

e-ISSN: 2502-5457

DOI: http://dx.doi.org/10.30998/formatif.v8i1.2304

Adinugraha, F. (2017). Media pembelajaran biologi berbasis ecopreneurship. Formatif:Jurnal Ilmiah Pendidikan MIPA, 7(3), 219-233. http://dx.doi.org/10.30998/formatif.v7i3.2233

Apriyani, D.D. (2017). Pengaruh penggunaan media proyeksi terhadap hasil belajar matematika. Formatif:Jurnal Ilmiah Pendidikan MIPA, 7(2), 115-123. http://dx.doi.org/10.30998/formatif.v7i2.1828

Dwija, I. W. (2008). Hubungan antara konsep diri, motivasi berprestasi dan perhatian orang tua dengan hasil belajar Sosiologi pada siswa kelas II Sekolah Menengah Atas unggulan di Kota Amlapura. Jurnal Pendidikan Dan Pengajaran UNDIKSHA, 41(1), $1-17$.

Hasibuan \& Moedjiono. 2009. Proses Belajar Mengajar. PT. Remaja Rosdakarya: Bandung

Kahar; M S. (2017). Analisis minat belajar mahasiswa terhadap penggunaan alat peraga neraca cavendish. Science Education Journal, 1(2), 73-83. http://doi.org/10.21070/sej.v1i2.1177

Kahar, M. S. (2017). Analisis kemampuan berpikir matematis siswa SMA kota Sorong terhadap butir soal dengan graded response model tinggi dan perhatian suatu teorema atau khususnya berpikir matematis tingkat penyekoran graded response model (GRM), merupakan salah satu pendek. Jurnal Keguruan Dan Ilmu Tarbiyah, 2(1), 11-18. http://doi.org/10.24042/tadris.v2i1.1389

King, P. M., Kendall Brown, M., Lindsay, N. K., \& VanHecke, J. R. (2007). Liberal arts student learning outcomes: An integrated approach. About Campus, (October), 2-9. http://doi.org/10.1002/abc.2

Puspitorini, R., Prodjosantoso, A. K., Subali, B., \& Jumadi, J. (2014). Penggunaan media komik dalam pembelajaran IPA untuk meningkatkan motivasi dan hasil belajar kognitif dan afektif. Cakrawala Pendidikan, 3(3), 413-420. https://doi.org/10.21831/CP.V3I3.2385

Rasul, S., Bukhsh, Q., \& Batool, S. (2011). A study to analyze the effectiveness of audio visual aids in teaching learning process at uvniversity level. Procedia - Social and Behavioral Sciences, 28, 78-81. http://doi.org/10.1016/j.sbspro.2011.11.016

Savander-Ranne, C., \& Kolari, S. (2003). Promoting the conceptual understanding of engineering students through visualisation. Global Journal of Engineering Education, 7(2), 189-200.

Shui-fong Lam; Rebecca Wing-yi Cheng and William Y. K. Ma. (2009). Teacher and Student Intrinsic Motivation in Project-Based Learning. Instructional Science, 37(6), $565-578$. 